\title{
The Challenges of Wood as a Play and Playground Material
}

\author{
Ade Adedokun \\ Dept. of Architecture, Joseph Ayo Babalola University, \\ Ikeji-Arakeji,Osun-State
}

\section{Doi:10.5901/mjss.2014.v5n2p97}

\begin{abstract}
This paper explores the modern uses of wood as a play and playground material. Wood as a natural material which has both the physical and aesthetic values, workability, environmental sustainability, flexibility of space arrangement, dry construction, industrial production and comparative cost effectiveness are discussed in this work. Wood has a high strength to weight ratio making it an attractive framing material. Some species are highly resistant to rot, corrosion and marine damage. there is no doubt of other potentials for the uses of wood in development, an example of which is in the tourist industry. Playground can be significant for social, cultural and tourist programmes, and wood can be a useful material for building plays and playground which give challenges in physical capabilities, improved mental image and the moral and psychological behaviour of people. Techniques of using wood as playground materials for the children in Nigeria are discovered.
\end{abstract}

\section{Introduction}

It is generally acknowledged that wood plays a major role is socio-economic development. In particular, as fuel wood, it is acknowledged that it occupies a general place in both rural and urban energy systems owing to the importance of the domestic consumption for which it is mainly used. In the rural community, the role of fuel wood is seen as a complex function with many connections with the rural economic systems for example, the land use systems, agricultural practices, social systems and industrial systems. In industrial systems for instance the use of wood is important not only as fuel wood but also as material for industries such as lumbering and paper/pulp industries. Wood is also significantly used for construction. Wood is very durable and there are numerous finishes available to protect and enhance the natural beauty of the material. These sealants and protective finishes promote its durability. If well protected and well installed, timber can last for centuries with minimum maintenance (Sturges, 1991). Insurance companies are now recognizing the favorable construction cost and fire resistance of engineered timber construction (FAO, 2002).

\section{Wood as Playing Materials Playgrounds}

Neighborhood and school playgrounds are places that kids play, get fit and make friends. We expect playgrounds to be safe and clean environments for children to play in. However, too many playgrounds across America have unsafe play equipment and are not well-maintained. (Healthy Schools Network, 2010). Children of all age groups, diverse background and culture have one thing in common. They enjoy playing. Play activities take different forms in different societies. It could be story telling at night in some African regions and a little more formalised play activities in the urban regions of the world. Children are more vulnerable to envi-ronmental health hazards because their bodies are still growing. Proportionally, they eat, drink, and breathe more per pound of body weight than adults. Children like to explore, which can expose them to more environmental threats than adults. But, they also do not know how to identify and protect themselves from these hazards. (Healthy Schools Network, 2010). The name of the game is the same everywhere play. Organized play activities in the Western sense has also been around in Nigeria for some time especially in the nursery and primary education systems.

In play activities some objects (equipment) are involved. The most common are the metal equipments with its range of swings, slides, see-saw, climbers etc. the materials metal has been well explored, although a lot of problems and disadvantages are attached. Because of the disadvantages attached to the use of metals as play materials, there's need to explore possible challenges of others materials.

The materials that readily come to mind would be that, which is readily available, replaceable, cheap to procure and install, safe and yet satisfies that basic requirements for play activities. Several materials within the Nigerian environment come to mind. E.g. wood, sand, clay, water etc. Of these materials wood satisfies the condition for both two 
and three dimensional objects. It is particularly stable and rigid and thus enjoys advantage over others. Wood material has been around since the down of times and man has used it extensively for his building, boat, sculptures and household objects. Wood is available and durable (in some form such as in chemical seasoning and in impregnation). It is also adaptable to a variety of uses. One of the important advantages of wood is its adaptability to nailing, screwing, polishing, planning and saw milling. Other advantages of the timber include availability, workability, and environmental sustainability, flexibility of space arrangement, dry construction, industrial production and comparative cost effectiveness (Gregory, 1984; Nolan 1994 and Whitelaw, 1990)

It is easy to handle and complicated machinery are unnecessary. Also, wood can be used successfully indoors as a major building component e.g. for posts and beams, as furnishing and ornaments, and for outdoors, as a street furniture and for a play object. In his numerous Landscape projects, Friedberg (1976) explored and demonstrated how wood can e successfully used outdoors for play materials for children of all age groups. (Fig. 1)

In these works (Friedberg, 1976) multiples of design, adaptable to many kinds of playgrounds, public, quasi-public as well as private places were assembled in many different kinds of sites. The design performance required by particular plying materials can be more flexibly matched by selecting wood of the appropriate density, compressive and tensile strength, colour, texture and fire resistance (Anderson, 1970). A play unit system effectively challenges a child's physical capabilities, teaching him how high he can go and how strong he can be. He learns how long he can balance on one hand and how much physical effort he can endure. The units were assembled to create a silhouette of verticals which would penetrate the sky plan. A series of inter-connected stepping columns, vertical climbing unit and raised horizontal elements satisfy the play requirements. Assembled play units were almost elevated to a work of the. All the forms created are useful not only in the U.S.A. but in other parts of he world including Nigeria. Wood from a number of tree species in Nigeria has properties which recommend them for use in building plays. Examples include timber teak, mahogany, afara, opepe.

\section{Properties, Availability, Preservation and Preparation of and Wood Examples in Nigeria}

Available timber species vary widely in properties, characteristics, and appearance. Their selection depends upon factors such as appearance, dimensional strength and stability, available species, durability and ease of preservation. The key clement in the use of wood is its identification and suitability for a particular purpose. Timber species can be identified by natural colours and grain characteristics. Wood as playground has low manufacturing process energy and benign air emissions (Townsend and Wagner, 2000). Timber is an excellent insulator against hot or cold weather. The old "loghouse" remains a model for minimum energy consumption in buildings (Ogunsote, 1993).

Another example of timber is the mahogany which has slightly coarse texture and more pronounced grains than teak upon slicing. It is heavy and hard. The Sapele species has the properties of Mahogany except that it is harder and heavier. Teak (Taconia) species is a tall, hard and less bulky than the two species earlier mentioned. It is common in reforestation projects. It's average width (about $300 \mathrm{~mm}$ ) makes it too uneconomical in timber industry but useful when used wholesomely in electrification project (stanchions) and building construction. It's hardness, fine grain characteristics and varying width makes it easily converted as a play and play equipment materials. It is the wood commended for design in the present work.

In conversion before use, the debarked wood is cut into desirable sizes that are uniform in thickness and length. The wood is then seasoned (the process of reducing the moisture content to the required level. Specified by the grade and use). There are various ways of seasoning timber.

For air drying method, planks are simply exposed to the outside air after debarking and carefully stacked so air can circulate through. Mechanically, wood is kilned by placing it in huge ovens where the temperature and humidity can be carefully controlled. The exposure of wood to insect attacks, rots, necessitates the need for preservation and is one of the initial factors to be considered in selecting wood for a particular job where durability against fungus and insect is essential. Timbers, given suitable preservative treatment, will no doubt repay any initial high investment. Wood should be treated before installation to ensure that end sections and other areas would be inaccessible to pests, once installed.

The challenges demonstrated by the potential uses of wood calls for innovative approach in designs. Already, some architects have employed the material creatively and have made wood adaptable to several forms (including rectangular square and tubular) in order to arouse the curiosity in. children. The forms explored and the opportunity it creates is the 'catch' in which the children's sense of imagination and challenge is enhanced. In the following sections, examples of equipments (figs. 1-6) designed and for which wood is recommended as the materials are discussed. 


\section{Discussions/Description of Play Eq'ments for which Wood is Recommended}

\subsection{Graduated Bar Pyramid (Fig. 1)}

The graduated bar pyramid is used by children between the ages (3-8) years. It is basically for climbing, balancing, jumping, somersaulting and hide and seek. The materials involved include wood, nuts bolts and sand. The wood members are laid in a vertical and horizontal planes whereby the bolts and nuts are used to hold them together. The space required for the equipment varies from about $1.6 \mathrm{~m} \times 4 \mathrm{~m}$ to $2.5 \mathrm{~m} \times 6 \mathrm{~m}$.

\subsection{Adventure Pyramid (Fig. 2)}

The adventure pyramid is used by children of all age groups. The equipment satisfies all play activities such as locomotion, adventure, relaxation etc. The adventure pyramid equipment could be used for climbing, jumping, hide and seek, sliding, crawling etc.

The materials used include wood, ropes, nuts, bolts, concrete cement and sand. The equipment itself comprises of a, ladder made of wood which leads unto a wooden panel and is supported by four (4) wooden posts. Hanging unto the posts are a couple of rope which has a wooden slide. At the end of the slide is the pyramid with a wooden base and a. climber/ladder by-the side. The basic space requirement varies but has a minimum dimension of $3 \mathrm{~m} \times 4 \mathrm{rn}$.

\subsection{Shelter Pyramid (Fig. 3)}

The shelter pyramid is an equipment which is fenced round with two end-openings. The equipment is good for all ages for adventure, balancing, running, walking, hide and seek, jumping, crawling etc. The equipment is buried in sand with surrounding paly_fence: Materials used includes, wood, nuts, bolts, concrete cement and sand.

The shelter pyramid is open at the ends with a major entrance and a Wooden platform (base). The woods are sliced into equal halves and nailed to the posts acting as the walls of the pyramid. They are nailed unto the post with the bolts and nuts which is also used to hold the posts at the top (peak). All the posts are buried firmly to the ground with concrete cement.

\subsection{Monkey Bridge (Fig. 4)}

The monkey bridge is used by children between the ages of 4 (four) and 12 (twelve) years for climbing, balancing, jumping and adventure. The materials used for the bridge includes wood, polyfiber (rope), concrete, cement, sand, nuts and bolts.

The equipment is anchored (fixed) to the ground by a polyfiber-rope from one end to the other, with posts breaking them off at intervals. The ropes on the lower side have wooden battens set at intervals where children walk and try 0 balance on them. The rope on the upper side is laid movement and balance for the adventurous kids. The space required varies with minimum space of $7 \mathrm{~m}^{2}$.

\subsection{Play Houses (Fig. 5)}

The play house is good for age group 2-8 years with a space requirement of 48.5ni using materials such as wood, nuts, bolts, sand and cement. The general idea, is an imitation of a house. It challenges children to climb, play, hide and seek, run and jump, balance, etc. the structure is anchored to the ground by the use of concrete cement and the other support materials are held together with bolts and nuts. The equipment is elevated, to aid climbing. It has a typical itched roof with posts acting as supports for the roof and walkway made out of wood with the support. being anchored to the ground leading to another replica building so that children can move freely around the buildings. The play-lot is edged by low wood-ballards for balancing and stepping which is equally part of the games.

\subsection{Playtent (Fig. 6)}

The playtent is a combination of swings and climbers used by children between the ages of 3-12 years and 12 with a space requirement of $\left(3 \mathrm{~m}^{2}\right)$. The materials used involve wood, rope, nuts, bolts, cement arid sand. 
The use of high tension ropes are engaged For the ladded (climber) to aid children climb to the top. The structure consist of four wooden posts which are anchored to the ground by the use of concrete. These wooden posts now carry the load of a trampoline which is framed for kids to jump, bounce and balance or roll on.

\subsection{Platform Cluster (Fig. 7)}

The platform clusters consists of slides, balances and ladder. It is an equipment designed for children between the ages of 2-6 years. The equipment has various measurement with minimum space requirement of $2.5 \mathrm{~m}^{2}$.

The equipment is supported with four (4) posts with a wooden platform at the upper level. The wood on the upper level is split into two and anchored onto the support by the use of bolts and nuts. Slightly below the platform is a slide, cylindrical in shape, which the kids hold on to and slides down. On the other side of the cluster is a long wooden pole, cylindrical and supported at the base for children to walk on, land, balance before getting to the cluster.

In all, the wood recommended for user should be debarked, seasoned and treated. It should be cut into varying diameters and lengths depending on the use for which it is designed. Examples of these have been designed for use and experimentally installed in Grace Children's School, Gbagada by the present author.

\section{Conclusion}

The above discussions no doubt show the significance of wood as a potential material for playing equipments. They also shows that a lot can be achieved by using local materials to develop games and promoting culture in Nigeria. Thus, a lot of traditional games such as 'Ayo' can be introduced and promoted as recreational activities. In addition to maintaining or promoting the cultural values, there is also the advantage of incorporating them innovatively in the landscape planning design and in the concept of space and use of materials in developing countries.

\section{Reference}

Anderson, L.O. (1970). Wood-frame House Construction. US Department of Agriculture.

FAO (2002). Environmental and Energy Balances of Wood Products and Substitutes. Rome.

Gregory, N. (1994). The Culture of Using Timber as a Building Material in Australia. The Pacific Timber Engineering Conference, August.

Healthy Schools Network, Inc. (2010). Playgrounds \&Toxic Threats www.NationalHealthySchoolDay.org Pp.1-6

Nolan, G. (1994). The Culture of Using Timber as a Building Material in Australia. Proceedings of the Pacific Timber Engineering Conference. Australia.

Ogunsote, O.O. (1993). An Introduction to Building Climatology - A Basic Course for Architecture Students. Ahmadu Bello University Press, Zaria.

Oyetola, E.B. (2001). Fundamentals of Timber Structure Designs Simply Explained. Yetma Associates, Kaduna.

Sturges, W.G (1991). Towards a Definition of Sustainable Construction Technologies of Framework of Performance Criteria Evaluating Three Wooden Light Frame Floor and Roof Structural Systems in Cascadian Region. Unpublished report, University of Oregon.

Townsend, P. and Wagner, C. (2000). Timber as a Building Material: An Environmental Comparison against Synthetic Building Materials. National Association of Forest Industries.

Whiltelaw, S. (1990). Architects love Timber. Australian Forest Industries Journal. March.
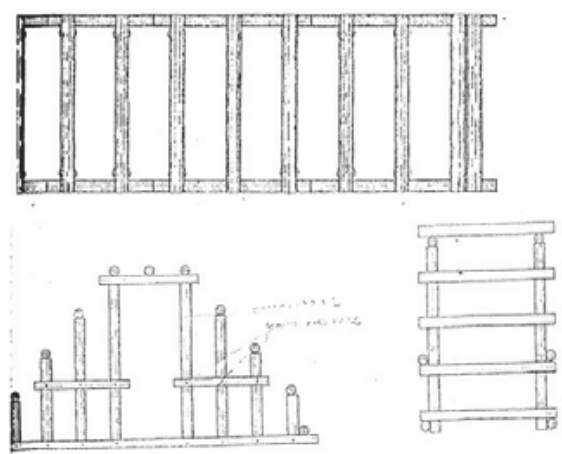

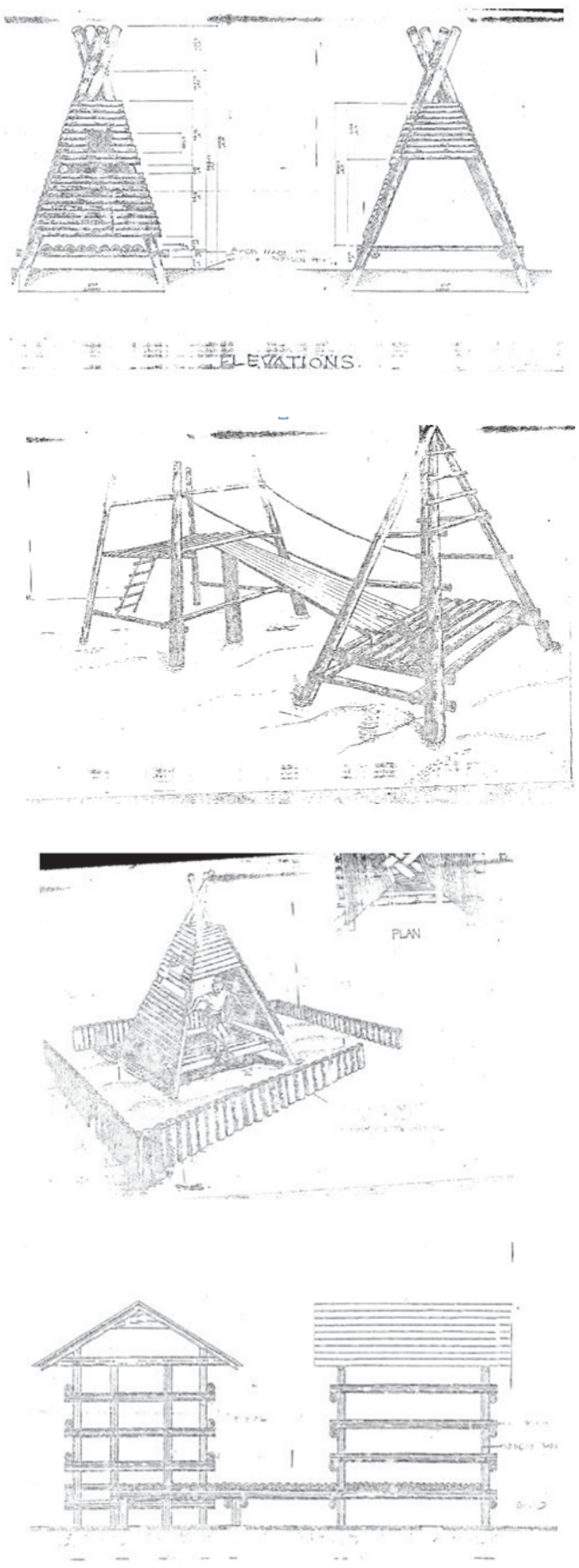

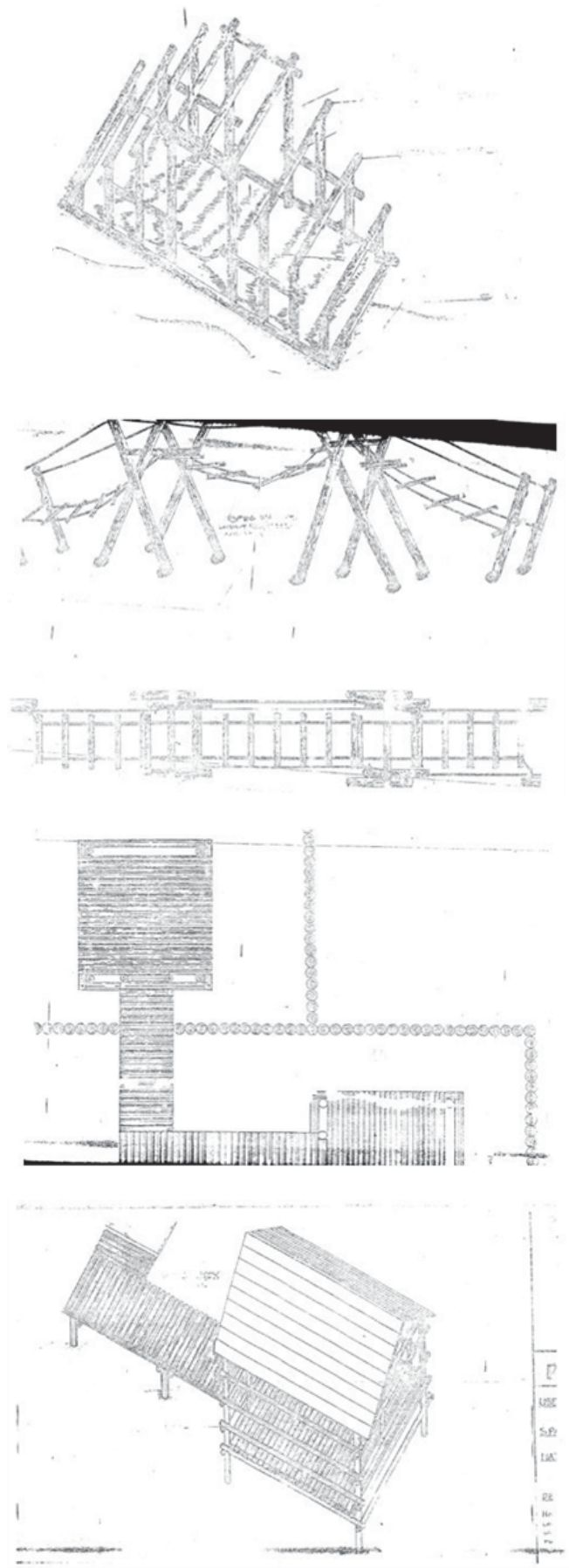